\title{
Breathability and Safety Testing of Personal Protective Equipment: "Human-comfort" Factor Remains Undefined
}

\author{
Aditya Kapoor ${ }^{1}$, Arvind Kumar Baronia ${ }^{2}$, Afzal Azim $^{3}$, Gaurav Agarwal ${ }^{4}$, Narayan Prasad ${ }^{5}$, Richa Mishra ${ }^{6}$, \\ Vivek Anand Saraswat ${ }^{7}$
}

\begin{abstract}
Healthcare systems all over the world have been enormously affected by the COVID-19 pandemic. Healthcare workers (HCWs) taking care of these patients need personal protective equipments (PPEs) standardized for full protection from droplets and aerosols carrying viral load to variable distances. There has been a surge of manufacturers supplying these protective gears in India and regulatory agencies have issued technical specifications pertaining to PPEs focusing solely on synthetic blood penetration tests (SBPTs) and keeping the upper limit of nonwoven fabric to $95 \mathrm{~g} / \mathrm{m}^{2}$ (GSM). These PPE specifications are silent on air permeability (AP) and water/moisture vapor transmission rate (WVTR/ MVTR) of the fabric. As a result, most of the PPE kits, despite having appropriate SBPT certifications from regulatory agencies, have extremely poor permeability and breathability. The acceptability of PPEs by HCWs can be vastly improved when the end-users are proactively invited to participate in "comfort testing" of PPEs before getting issuance of certification for marketing. "Field testing" or "end-user trials" in which HCWs don the PPE and assess it for comfort while performing different types of clinical work, e.g., in intensive care units (ICUs), operation theaters, cath labs, etc., also takes into account a hitherto often ignored "human-comfort-factor" that not only enhances the understanding of HCWs about the need for the PPEs but can also motivate them to use it without worrying about discomfort. We hereby propose that comfort fit testing (COmfort and Material Fit is an Obviously Required Test) should be a part of the mandatory testing and certification process for PPE, so that the industry invests wisely in manufacturing PPE kits that are not only certified for fabric but are also tested for comfort factors.

Keywords: COVID-19, Comfort fit testing, Healthcare workers, Personal protective equipment.

Indian Journal of Critical Care Medicine (2021): 10.5005/jp-journals-10071-23598
\end{abstract}

\section{INTRODUCTION}

The enormous impact of the COVID-19 pandemic on global healthcare systems has also seen a huge demand for personal protective equipments (PPEs) that are needed to protect healthcare personnel from droplets and aerosols carrying viral loads. Various components of PPE include coverall/gowns, head cover, shoe covers, face-shield, goggles, gloves, and appropriately certified face masks or respirators. Although all components complement each other for safety, the coveralls/gowns which form an integral part of PPE should be designed to completely cover the torso of healthcare workers (HCWs), ensuring a complete $360^{\circ}$ protection. The current paper reviews the following issues that are specific to COVID-19 in the Indian setting:

- What to use: Coveralls vs gowns

- Current Ministry of Health and Family Welfare (MoHFW) technical specifications and laboratory certification guidelines for PPEs

- Importance of breathability and comfort of PPEs

- Incorporation of Breathability and Comfort parameters into technical specifications and development of different levels of comfort testing of PPEs

- Messages to industry, medical professionals, and medical administrators

\section{Safety of Coveralls and Gowns}

Intuitively speaking, coveralls which drape the entire body, from head to toe offer most robust protection to HCWs. However, gowns are much easier to don and in particular, easier to take off. Better familiarity of HCWs with gowns also means that they are more likely to use and remove them correctly, and therefore need less training for use. Gowns, however, often have the limitation
${ }^{1}$ Departments of Cardiology, Sanjay Gandhi Postgraduate Institute of Medical Sciences, Lucknow, Uttar Pradesh, India

${ }^{2,3}$ Department of Critical Care Medicine, Sanjay Gandhi Postgraduate Institute of Medical Sciences, Lucknow, Uttar Pradesh, India

${ }^{4}$ Department of Endocrine Surgery, Sanjay Gandhi Postgraduate Institute of Medical Sciences, Lucknow, Uttar Pradesh, India

${ }^{5}$ Department of Nephrology, Sanjay Gandhi Postgraduate Institute of Medical Sciences, Lucknow, Uttar Pradesh, India

${ }^{6}$ Department of Microbiology, Sanjay Gandhi Postgraduate Institute of Medical Sciences, Lucknow, Uttar Pradesh, India

${ }^{7}$ Department of Gastromedicine, Sanjay Gandhi Postgraduate Institute of Medical Sciences, Lucknow, Uttar Pradesh, India

Corresponding Author: Arvind Kumar Baronia, Department of Critical Care Medicine, Sanjay Gandhi Postgraduate Institute of Medical Sciences, Lucknow, Uttar Pradesh, India, e-mail: arvindbaronia@ hotmail.com

How to cite this article: Kapoor A, Baronia AK, Azim A, Agarwal G, Prasad N, Mishra R, et al. Breathability and Safety Testing of Personal Protective Equipment: "Human-comfort" Factor Remains Undefined. Indian J Crit Care Med 2021;25(1):12-15.

Source of support: Nil

Conflict of interest: None

that some designs may offer cover only up to the knee or just below the knee level, and therefore may not provide continuous whole-body protection. Previous reports have cited that while HCWs were more comfortable wearing gowns as long as there was limited bending and lifting, no significant difference was reported in terms of, perceived safety and comfort and the choice of 
coveralls over gowns was governed by the availability and individual preference of the HCW. ${ }^{1}$ Keeping this in mind at present according to Ministry of Health and Family Welfare (MOHFW) guidelines, ${ }^{2}$ both coveralls and gowns are considered to be equally acceptable (with or without apron).

\section{Ministry of Health and Family Welfare Technical Specifications and Laboratory Certifications}

It is extremely important to have balanced standards and protocols in place to test truly if the body-wear reduces the likelihood of infected body fluids penetrating and contaminating the underlying clothes or skin. In view of the COVID-19 pandemic, the MoHFW guidelines for coveralls and gowns mandates ISO 16603 class III exposure pressure or equivalent for synthetic blood penetration test (SBPT). Six classes of grading from class I to VI are available (Table 1). The other mandatory tests are given in Table 2.

However, the testing agencies have been found to ignore the SBPT upper limit of $3.5 \mathrm{kPa}$ for COVID-19 protective coveralls and gowns and it was noted that many samples were failed by the agencies as they erroneously placed the SBPT test upper limit of $20 \mathrm{kPa}$.

\section{Breathability and Comfort}

Since the use of PPEs is invariably associated with sweating, it is important that the fabric should be breathable enough to avoid obvious discomfort to the HCW who often need to don the PPE suits for $6-8$ hours, or sometimes even longer. Breathability of a fabric is reflected by its ability to dissipate thermal energy or sweat generated by the body by diffusion to the outside by moisture vapor transmission, thereby allowing comfort to the user.

The human body even at rest generates heat and heat generation increases as physical activity increases. Heat generation

Table 1: International Organization for Standardization (ISO) 16603 and 16604 classes for ranking garments

\begin{tabular}{lll}
\hline Class & Test & Pressure criteria $(\mathrm{kPa})$ \\
\hline Class I & ISO 16603 and 16604 & 0 \\
Class II & ISO 16603 and 16604 & 1.75 \\
Class III & ISO 16603 and 16604 & 3.5 \\
Class IV & ISO 16603 and 16604 & 7.0 \\
Class V & ISO 16603 and 16604 & 14.0 \\
Class VI & ISO 16603 and 16604 & 20.0 \\
\hline
\end{tabular}

Table 2: Various standard tests for the personal protective equipment

\begin{tabular}{|c|c|c|}
\hline S. no. & Applicable standards & Purpose \\
\hline 1 & ASTM F1980 & $\begin{array}{l}\text { Standard guide for accelerated aging of sterile barrier systems for medical } \\
\text { devices }\end{array}$ \\
\hline 2 & EN 14126:2003 & $\begin{array}{l}\text { Protective clothing. Performance requirements and test methods for protec- } \\
\text { tive clothing against infective agents }\end{array}$ \\
\hline 3 & ISO 16604:2004 or ASTM F1670 & $\begin{array}{l}\text { Standard test method for resistance of materials used in protective clothing } \\
\text { to penetration by synthetic blood }\end{array}$ \\
\hline 4 & ASTM F1671 & $\begin{array}{l}\text { Standard test method for resistance of materials used in protective clothing } \\
\text { to penetration by blood-borne pathogens using Phi-X174 bacteriophage } \\
\text { penetration as a test system }\end{array}$ \\
\hline 5 & EN 20811 & Determination of resistance to water penetration-hydrostatic pressure test \\
\hline 6 & ASTM D5034 & $\begin{array}{l}\text { Standard test method for breaking strength and elongation of textile fabrics } \\
\text { (grab test) }\end{array}$ \\
\hline 7 & ASTM D5733 & $\begin{array}{l}\text { Standard test method for tearing strength of non-woven fabrics by the } \\
\text { trapezoid procedure }\end{array}$ \\
\hline 8 & ASTM D6319 & Specification for nitrile examination gloves for medical applications \\
\hline 9 & ISO 11607 & Packaging for terminally sterilized medical devices \\
\hline 10 & ISO 811 & $\begin{array}{l}\text { Hydrostatic pressure method for determining the resistance of fabrics to } \\
\text { penetration by water. The method is applicable to all types of fabrics which } \\
\text { are intended to be water resistant, whether or not they have been given a } \\
\text { water-resistant or water-repellent finish }\end{array}$ \\
\hline 11 & ISO 16602 & $\begin{array}{l}\text { Minimum performance classification and labeling requirements for } \\
\text { protective clothing designed to provide protection against chemicals }\end{array}$ \\
\hline 12 & ISO 13982-1 & Chemical protective clothing for protection against airborne particles \\
\hline 13 & $\begin{array}{l}\text { ISO } 16603 \text { classes of exposure pressure or its } \\
\text { equivalent }\end{array}$ & $\begin{array}{l}\text { Tested for penetration resistance to synthetic blood and grouped into } \\
\text { specific classes in response to applied pressure according to ISO } 16,603 \text {, } \\
\text { indicating that higher class fabrics withstand higher pressure. Various classes } \\
\text { from I to } \mathrm{VI} \text { are available. Class III and above are usually recommended for } \\
\text { PPE tolerating up to } 3.5 \mathrm{kPa}\left(35.7 \mathrm{~cm} \mathrm{H}_{2} \mathrm{O}\right)\end{array}$ \\
\hline 14 & $\begin{array}{l}\text { EU standard directive } 86 / 686 / \text { EEC, EN } 166 / 2002 \text { or } \\
\text { ANSI/SEA Z87.1-2010 or its equivalent }\end{array}$ & Goggles and face shields should comply with the quoted quality standards \\
\hline 15 & $\begin{array}{l}\text { EU standard directive 93/42/EEC Class I, EN 455, EU } \\
\text { standard directive 89/686/EEC Category III, EN } 374 \\
\text { or ANSI/ISEA 105-2011, or ASTM D6319-10 or its } \\
\text { equivalent }\end{array}$ & Gloves preferably nitrile should comply with the quoted quality standards \\
\hline 16 & EN ISO 20345 & Shoes should comply with the quoted quality standards \\
\hline
\end{tabular}


is matched by heat dissipation from body surfaces and evaporation of sweat and the resultant cooling effect helps the body temperature to remain controlled. However, improper clothing including PPE aggravates heat and moisture trapping inside the garment which a HCW wears and the wearer is likely to experience rise in body temperature leading to more and more discomfort, with the passage of time, within 1-2 hours causing exhaustion, heat stroke, and even deterioration in consciousness.

Humans lose body heat through three primary mechanisms that need to be understood while designing/choosing a fabric for coverall.

- Evaporation: (55\%) Evaporative cooling is the absorption of energy as water (sweat) changes its form from liquid to vapor, which is also known as "heat of vaporization". This heat is drawn away from the body with the vapor, leaving the skin surface cooler.

- Convection and conduction: (35\%) It is the heat lost to air or materials that come in contact with the skin. This type of heat loss is proportional to the temperature difference between the skin surface and the material contacting the skin.

- Radiation: (10-15\%) Radiant heat loss is off-set by infrared radiation absorbed by the body from other heat sources, such as the sun, and ambient light and may lead to a net gain in working situations.

\section{Two Important Parameters Merit Inclusion in Personal Protective Equipment Testing}

\section{Moisture Vapor Transmission Rate}

Which is measured by the assessing the quantity of moisture vapor through a fabric during a specified time period and is reported as grams per square meter $\left(\mathrm{g} / \mathrm{m}^{2}\right)$ under defined temperature and humidity. ${ }^{3}$ Higher values indicate better moisture vapor removal and therefore better breathability.

\section{Air Permeability (AP): Permeation}

Air permeability is a measure of the ability of a fabric to permit passage of air through the fabric's interstices. This is dependent on various factors like fiber porosity, fabric thickness and density, etc. Hygroscopic fibers like cotton can rapidly absorb moisture with changes in the ambient humidity, hence increasing the resistance to air or water permeation due to swelling and closeness of the pores in the fabric.

The breathability is dependent on the type of fabric used. Coveralls are generally manufactured using fabrics, most commonly non-woven polypropylene fibers. In common language, these fabrics are often known as Spunbond, Meltblown, Spunlace, etc., and are usually available in various compositions like spunbond meltblown spunbond (SMS), spunbond, meltblown, spunbond, meltblown (SMMS), etc.

Laminated fabrics are less breathable than coveralls made with SMS type polypropylene. Laminated fabrics are made from a substrate layer of either polypropylene, or a layer of bicomponent fibers with a polyester core and a polyethylene sheath.

The breathability of laminated fabrics can vary according to changes in the size of the micropores of the polyethylene film. The larger the micropores, the more breathable will be the fabric, although this may also mean less protective than a laminate with small micropores. Lamination material with appropriate size of micropores for good moisture vapor transmission rate (MVTR) is manufactured by very few good companies and the material is not easily available and incurs huge costs. More layers also means more heavy fabric (GSM — grams per square meter) and it adds to physical and chemical resistance at the cost of comfort to the HCW. Coveralls, which are laminated only at the stitch lines, are more breathable and also add to the protection by making the coverall seamless.

The current government specifications for PPEs are silent in terms of AP and water vapor transmission rate (WVTR)/MVTR. In the absence of clarity on specifications for PPEs related to these points, some of the available kits, despite having appropriate certifications from regulatory agencies regarding the fabric material, have extremely poor AP, WVTR/MVTR, and breathability.

As a general rule, all PPEs produce a significant impediment to heat loss because of their impermeability which reduces evaporation. Hence, HCWs often experience increases in skin and core temperatures which are further amplified in hot and/or humid conditions, an important factor in Indian conditions. ${ }^{4-6} \mathrm{~A}$ recent study comprising 4,308 HCWs across 161 COVID-19 hospitals in China found that nearly $30-40 \%$ reported heavy sweating, irritation, skin injuries and rashes, redness, and itching. The three most common forms of injury were device-related pressure injuries, moisture-associated skin damage, and skin tears over various parts of the body. ${ }^{7}$

This is a great cause of concern because excessive sweating can not only reduce the professional ability of the HCW to render effective care but can also be detrimental to the personal health of the HCW.

It is therefore very important for current guidelines to include technical specifications pertaining to AP and WVTR/MVTR (respectively, $100-150 \mathrm{~L} / \mathrm{m}^{2} /$ minute for AP and $400-500 \mathrm{~g} / \mathrm{m}^{2}$ / day for WVTR/MVTR), compliant with ASTMF96 standards or its equivalents. Despite complying with many of the mentioned technical specifications and claims of the manufacturers that their PPE kits are ergonomically designed, it is very important to validate these claims by "field testing" or "end-user trials" in which HCWs don the PPE and assess it for comfort and different work-performance indices. The UK PPE regulations (Personal Protective Equipment at Work Regulations 1992) also mention that, the institutions should choose a PPE that gives maximum protection and is associated with minimum discomfort. ${ }^{8}$

We propose an acronym COMFORT (COmfort and Material Fit is an Obviously Required Test) which should include the following: (a) Body heat impact and sweating assessment for 2 hours in an air-conditioned environment without any physical activity and assessment for sweating, dizziness, and feeling of fainting. (b) Flexibility testing of PPE kits with assessment of ability to perform patient care and nursing activities like Ryle's tube feed, hanging intravenous fluid on bed rails, sit comfortably on chairs with knee flexion to test for tightness of fit, and tearing of fabric, (c) and any additional points which the HCW wish to give feedback about including ease of donning/doffing, need for extra ties/laces/velcro to avoid slippage of shoe covers, etc.

A "comfort fit PPE assessment study" was performed among intensive care unit (ICU) personnel who were previously in good health and volunteered to take part in a pilot study. A total of 18 PPE kit samples were evaluated, and the donning period was limited to the time when the volunteers experience serious discomfort in a centrally air-conditioned ICU with ambient temperature $22-24^{\circ} \mathrm{C}$ and humidity $40-55 \%$. Excessive sweating was experienced within 1-2 hours in 12/18 (67\%) samples tested. 
Hence, despite having appropriate certifications for fabric safety, two-third of PPEs tested had severe issues related to breathability and comfort of use due to excessive sweating. Since such PPE kits are unacceptable for use by the HCWs, and likely to be returned to the manufacturers, it is very pertinent that the Government of India issues modified certification criteria for breathability so that such type of poor quality PPE kits are not manufactured at all.

Messages: We propose that the proposed COMFORT fit testing should be a part of the mandatory testing process for PPE assessment so that industry and healthcare institutions invest wisely in PPE kits that are not only certified for fabric safety but also for AP and MVTR.

The acceptability of PPEs by HCWs can be vastly improved when the end-users are proactively invited to participate in the selection and comfort testing of PPEs. Hospital administrators should perform trials wherein the HCWs don the PPEs and offer opinions especially about desired comfort parameters, prior to the placement of purchase orders. Participation and feedback of HCWs in selection and testing of PPEs in such a way shall not only take into account a hitherto often ignored "human-comfort factor" but will also motivate them to use PPEs without any sense of undue worry.

\section{References}

1. https://www.ncbi.nlm.nih.gov/books/NBK401160/.

2. https://www.mohfw.gov.in/pdf/Guidelinesonrationaluseof PersonalProtectiveEquipment.pdf.

3. Gokarneshan N, Rachel DA, Rajendran V, Lavanya B, Ghoshal A. Emerging Research Trends in Medical Textiles. Singapore: Springer; 2015.

4. Hostler D, Gallagher Jr M, Goss FL, Seitz JR, Reis SE, Robertson RJ, et al. The effect of hyperhydration on physiological and perceived strain during treadmill exercise in personal protective equipment. Eur J Appl Physiol 2009;105(4):607-613. DOI: 10.1007/s00421-008-0940-2.

5. Morley J, Beauchamp G, Suyama J, Guyette FX, Reis SE, Callaway $\mathrm{CW}$, et al. Cognitive function following treadmill exercise in thermal protective clothing. Eur J Appl Physiol 2012;112(5):1733-1740. DOI: 10.1007/s00421-011-2144-4.

6. Gr_elot L, Koulibaly F, Maugey N, Janvier F, Foissaud V, Aletti M, et al. Moderate thermal strain in healthcare workers wearing personal protective equipment during treatment and care activities in the context of the 2014 Ebola virus disease outbreak. J Infect Dis 2015.

7. Jiang Q, Song S, Zhou J, Liu Y, Liu Y, Chen A, Bai Y, et al. The prevalence, characteristics, and prevention status of skin injury caused by personal protective equipment among medical staff in fighting COVID-19: a multicenter cross-sectional study. Adv Wound Care (New Rochelle) 2020(7). DOI: 10.1089/wound.2020.1212.

8. https://www.hsimagazine.com/article/ppe-comfort-and-coolnessare-key/. 